\title{
Kajian Potensi Wisata Kuliner Pantai Ampenan
}

\author{
Rini S. Saptaningtyas ${ }^{1}$, Teti Handayani ${ }^{1}$, Ni Ketut Ayu Intan Putri Mentari Indriani ${ }^{1}$ \\ ${ }^{1}$ Program Studi Arsitektur, Fakultas Teknik, Universitas Mataram \\ Jl. Majapahit no 62, Mataram, Indonesia \\ *Email: rinisaptaningtyas@unram.ac.id
}

\begin{abstract}
Abstrak
Sejak ditetapkannya KEK Mandalika tahun 2017, Pulau Lombok kini menjadi salah satu tujuan utama wisata di Indonesia. Selain jenis wisata alam dan budaya yang ditawarkan, terdapat juga kuliner yang khas seperti plecing kangkung, ayam taliwang, sepat, bebalung yang disukai wisatawan. Aspek kuliner mempunyai peranan yang sangat kuat dalam keberhasilan pengembangan sebuah destinasi (Pepela \& O'Halloran, 2014), karena menikmati makanan lokal dapat memberikan peluang bagi wisatawan untuk mempelajari geografi dan budaya masyarakat setempat (Richards, 2002). Pemerintah Kota Mataram menyadari hal tersebut dan menyusun sebuah rencana pembangunan tempat wisata kuliner yang tidak hanya fokus pada kulinernya, namun juga keindahan alam, seni dan budaya. Dinas Pariwisata Kota Mataram bekerjasama dengan Fakultas Teknik Universitas Mataram melakukan studi kelayakan penataan tempat wisata kuliner kawasan pantai Kota Tua Ampenan, yang diharapkan menghasilkan kajian awal untuk menyusun perencanaan pembangunan dan dasar pengambilan keputusan. Kegiatan studi ini bersifat deskriptif kualitatif. Sumber data yang digunakan berupa data primer dari hasil observasi dan wawancara. Data sekunder diperoleh dari dokumen, literatur dan jurnal ilmiah. Berdasarkan hasil analisa, didapatkan kesimpulan bahwa Pantai Ampenan layak dan sangat berpotensi untuk dijadikan tempat wisata kuliner, karena posisinya yang dekat dari pusat kota, dapat memperkuat citra kawasan, mendukung revitalisasi, serta memiliki sarana dan prasarana memadai.
\end{abstract}

Kata kunci: Pulau Lombok, Kota Tua Ampenan, wisata, kuliner, potensi

\begin{abstract}
Since the establishment of the KEK Mandalika in 2017, Lombok Island has now become one of the main tourist destinations in Indonesia. In addition to the types of natural and cultural tourism offered, there are also special culinary delights such as plecing kale, ayam Taliwang, sepat, bebalung which tourists like. The culinary aspect has a very strong role in the successful development of a destination (Pepela \& O'Halloran, 2014), because enjoying local food can provide opportunities for tourists to learn about the geography and culture of the local community (Richards, 2002). The Mataram City Government is aware of this and compiles a plan to build a culinary tourism spot that not only focuses on culinary delights, but also natural beauty, arts and culture. The Mataram City Tourism Office in collaboration with the Faculty of Engineering, University of Mataram conducted a feasibility study on the arrangement of culinary tourism spots in the coastal area of the Ampenan Old City, which is expected to produce an initial study to prepare development planning and the basis for decision making. This study activity is descriptive qualitative. The data sources used are primary data from observations and interviews. Secondary data were obtained from documents, literature and scientific journals. Based on the results of the analysis, the conclusion is that Ampenan Beach is feasible and has the potential to be used as a culinary tourism spot, because of its close position from the city center, it can strengthen the image of the area, support revitalization, and have adequate facilities and infrastructure.
\end{abstract}

Keywords: Lombok Island, Ampenan Old Town area, tourism, culinary, potential

\section{Pendahuluan}

Pulau Lombok saat ini telah berkembang menjadi salah satu tujuan wisata di Indonesia, terutama setelah ditetapkannya Kawasan Ekonomi Khusus (KEK) Mandalika di tahun 2017 oleh pemerintah pusat. Pulau Lombok juga sudah dikenal luas oleh masyarakat internasional. Adapun jenis wisata yang ditawarkan di Pulau Lombok adalah wisata budaya, wisata alam dan wisata kuliner. Saat ini, wisata kuliner merupakan salah satu jenis wisata yang menjadi sebuah fenomena baru dalam pariwisata dan sangat berpotensi untuk dikembangkan. Hal tersebut karena kuliner di wilayah Indonesia sangatlah beragam dan memiliki cita rasa tersendiri.

Pulau Lombok sendiri telah dikenal dengan beberapa kuliner khas dan disukai oleh wisatawan nusantara dan wisatawan mancanegara. Tetapi tidak menutup kemungkinan panganan khas daerah ini perlahan akan tergerus waktu, zaman dan perubahan pola gaya hidup masyarakat. Menteri Pariwisata Arief Yahya menegaskan akan perlunya upaya perlindungan agar 
wisata kuliner berkembang dan mampu bersaing di era globalisasi saat ini. Hal ini membutuhkan kesiapan dan komitmen pemerintah daerah dalam meningkatkan potensi wisata kuliner di daerah.

Pemerintah Kota Mataram menyadari peran penting kuliner dalam industri pariwisata. Beberapa kawasan strategis yang menjadi tempat masyarakat berjualan aneka panganan di Kota Mataram telah mendapat sentuhan penataan sehingga terlihat lebih teratur dan terhindar dari kesan kumuh, contohnya di Jalan Udayana, di kawasan sekitar Lapangan Malomba (Taman Maritim) dan dibeberapa kawasan lain di Kota Mataram, tetapi keberadaan spot-spot kuliner tersebut dianggap masih belum dapat memenuhi kebutuhan pengunjung. Maka dairi itu, pemerintah Kota Mataram melalui Dinas Pariwisata Kota Mataram kemudian menyusun rencana untuk membangun tempat wisata kuliner di Kota Mataram yang penekanannya tidak hanya pada aspek makanannya, melainkan juga menawarkan keindahan alam, seni dan budaya. Gagasan tersebut menjadi latar belakang perlu adanya feasibility study tempat wisata kuliner kawasan pantai di Kota Mataram.

Adapun lokasi yang akan dilakukan feasibility study merupakan salah satu pantai di kawasan pantai Ampenan, yaitu Pantai eks Pelabuhan Ampenan. Lokasi ini dipilih karena merupakan salah satu kawasan strategis dan bersejarah. Kota Tua Ampenan dulu dikembangkan oleh Belanda sebagai pelabuhan untuk menyaingi dominasi kerajaan di Bali. Sebagai kota pelabuhan perdagangan internasional Ampenan sangat kosmopolit. Warganya termasuk Cina pendatang dan pemukim yang oleh Belanda kala itu dimanfaatkan sebagai tenaga kerja murah, juga komunitas Arab, Melayu dan Bugis. Keragaman budaya itu bisa ditemui di Jalan utama Yos Sudarso yang di satu sisi berdiri rukoruko kuno milik warga Tionghoa, di sisi lain terdapat barisan toko milik komunitas Arab yang menjajakan aneka barang, termasuk barang khas Timur Tengah. Sebagian besar bangunan Ampenan merupakan arsitektural kolonial (Belanda) yang mendapatkan pengaruh dari berbagai budaya, termasuk budaya setempat. Dalam perkembangannya, ciri khas ini mulai pudar karena ketiadaan pedoman pembangunan. Faktor penyebabnya adalah tidak adanya pedoman sebagai acuan dalam pengembangan kawasannya.

Berdasarkan hal di atas, Dinas Pariwisata Kota Mataram bekerja sama dengan Fakultas Teknik Universitas Mataram untuk melakukan feasibility study/studi kelayakan penataan tempat wisata kuliner kawasan pantai Ampenan di Kota Mataram. Kerjasama ini diharapkan dapat menghasilkan suatu kajian awal untuk menyusun perencanaan pembangunan dan sebagai dasar pengambilan keputusan.

\section{Tinjauan Pustaka}

Kata wisata kuliner berasal dari bahasa asing yaitu voyages culinaires (Perancis) atau culinary travel (Inggris) yang artinya perjalanan wisata yang berkaitan dengan masak-memasak. Menurut Asosiasi Pariwisata Kuliner Internasional (International Culinary Tourism Association/ICTA) wisata kuliner merupakan kegiatan makan dan minum yang unik dilakukan oleh setiap pelancong yang berwisata. Berbeda dengan produk wisata lainnya seperti wisata bahari, wisata budaya dan alam yang dapat dipasarkan sebagai produk wisata utama, tetapi pada wisata kuliner biasanya dipasarkan sebagai produk wisata penunjang (Besra, 2012). Kuliner masuk dalam sektor akomodasi yang menjadi salah satu sektor penting dari tujuh sektor dalam industri pariwisata. Sektor akomodasi tidak hanya menyangkut tempat tinggal atau penginapan sementara tetapi juga hal yang berhubungan di dalamnya yaitu ketersediaan makanan dan minuman (Leiper 1990, dalam Pitana, 2009: 64, dan Suteja, 2019). Aspek kuliner dapat mempengaruhi kepuasan perjalanan wisata, yang pada akhirnya mendorong untuk melakukan kunjungan ulang dan merekomendasikan sebuah destinasi kepada orang lain.

Wisata kuliner menjadi daya tarik kuat dan mampu meningkatkan kesejahteraan penduduk setempat. Pengeluaran untuk makanan mencapai sepertiga dari total pengeluaran perjalanan pariwisata itu sendiri, dimana makanan lokal menjadi komponen utama dalam sebuah aktivitas wisata dan industri pariwisata (Kivela \& Crotts, 2005 dalam Wijayanti, 2020). Aspek kuliner juga mempunyai peranan yang sangat kuat dalam keberhasilan pengembangan sebuah destinasi, melalui kolaborasi antara makanan lokal dengan budaya dan lingkungan dengan stakeholder, seperti restoran, hotel, dan agen perjalanan (Pepela \& O'Halloran, 2014 dalam Wijayanti, 2020). Menikmati makanan lokal memberikan peluang bagi wisatawan untuk mempelajari geografi dan budaya masyarakat setempat (Richards, 2002). Makanan terkenal dan berkualitas dapat dikembangkan menjadi produk wisata untuk meningkatkan minat kunjungan pada sebuah destinasi wisata. Salah satu contoh destinasi wisata yang banyak dikunjungi karena daya tarik makanannya, yakni Italia, dimana masakan dan anggur Italia mampu mendorong pertumbuhan industri pariwisata (Boyne et al., 2002; Hjalager \& Corigliano, 2000 dalam Wijayanti 2020).

\section{Metode Penelitian}

Kegiatan studi ini adalah deskriptif kualitatif dengan lokasi penelitian yaitu Kawasan Kota Tua Ampenan, tepatnya pada Pantai eks Plabuhan Ampenan. Adapun jenis data yang digunakan dalam penelitian 
ini adalah data kualitatif atau dalam bentuk deskripsi. Sumber data yang digunakan berupa data primer yang diperoleh melalui observasi dan wawancara. Serta data sekunder yang diperoleh dari dokumen atau literatur dan jurnal ilmiah.

Pengumpulan data dilakukan melalui observasi atau mengamati secara langsung aktivitas pariwisata yang berkaitan dengan kuliner. Pengumpulan data juga dilakukan dengan metode wawancara dengan pejabat pemerintah terkait seperti Dinas Pariwisata, dan Dinas PU Kota. Wawancara dengan tokoh masyarakat dan pemangku kepentingan, untuk mengetahui umpan balik masyarakat, sehubungan dengan adanya rencana penataan tempat wisata kuliner. Sedangkan data sekunder diperoleh melalui bahan publikasi yang diterbitkan oleh BPS, Bappeda, dan instansi lainnya yang berhubungan langsung dengan studi ini.

\section{Metode Pengumpulan Data}

Studi ini dibagi dalam dua tahap pengumpulan data. Tahap pertama di fokuskan kepada aktivitas desk research yang meliputi telaah pustaka dan pencarian data sekunder. Tahap kedua akan memfokuskan pada pencirian data primer melalui wawancara mendalam (indepth interview) dengan nara sumber terpilih baik dari kalangan pejabat pemerintahan, maupun masyarakat dengan metode random sampling.

\section{Pembahasan}

\section{Analisa Kesesuaian Lokasi dengan Peraturan Daerah dan Rencana Tata Ruang}

Berdasarkan RTRW Kota Mataram 2011 - 2031, Pola penggunaan lahannya adalah masuk kategori kawasan lindung/kawasan cagar budaya (ditandai dengan warna ungu). Sedangkan, menurut Perda Kota Mataram No. 5 tahun 2019 tentang Perubahan Atas Peraturan Daerah Rencana Tata Ruang Wilayah Kota Mataram tahun 2011 - 2031 bahwa lokasi yang dimaksud, berada pada Kawasan Lindung dengan Ketentuan Umum Peraturan Zonasi untuk kawasan perlindungan setempat yaitu sempadan pantai.

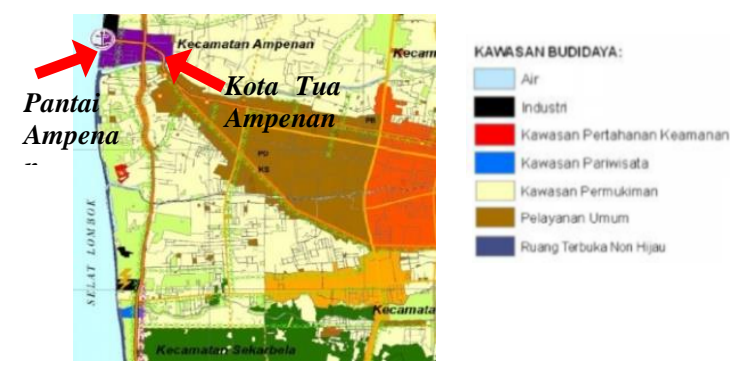

Gambar 1. Peta Tata Guna Lahan Kawasan Kota Tua Ampenan

Sumber: RTRW Kota Mataram Tahun 2011 - 2031
Dengan demikian kawasan Pantai Ampenan dapat dibangun menjadi fasilitas tempat wisata kuliner dengan beberapa kriteria, seperti: mampu meningkatkan nilai ekonomi Kota Mataram, tidak mengganggu fungsi ekosistem di dalam kawasan dan keanekaragaman hayati di dalamnya, serta mendapatkan persetujuan dari dinas instansi terkait yang berwenang.

\section{Analisa Lokasi dan Aksesibilitas}

Batas-batas Kawasan Eks Pelabuhan Ampenan sebagai alternatif lokasi tempat wisata kuliner adalah : sebelah Utara berbatasan dengan Jalan Pabean. Sebelah Selatan dengan Pantai Ampenan. Sebelah Barat dengan Kantor Pertamina dan sebelah Timur berbatasan dengan permukiman warga Kampung Melayu Ampenan Tengah.

Kondisi kawasan Pantai Ampenan saat ini sudah cukup tertata. Beberapa fasilitas yang tersedia bagi wisatawan adalah berupa kamar ganti pakaian dan kamar mandi. Sebagian besar area telah diperkeras dengan pasangan paving block sehingga tampak lebih rapi. Area tengah membentuk plaza dengan beberapa vegetasi sebagai aksen ruang luar, yaitu berupa tanaman bougenville dan pohon kelapa. Beberapa lapak penjual seafood bakar dan makanan ringan dibangun disisi Selatan Diantaranya adalah pelecing kangkung, ikan bakar, sate bulayak, aneka seafood, dll dengan harga yang terjangkau.

Biasanya masyarakat menghabiskan sore hari untuk menyaksikan matahari terbenam sembari makan di pinggir pantai ini.Terutama ketika liburan, tiba, tempat ini semakin ramai dikunjungi masyarakat. Dulu, Pantai Ampenam pernah menjadi pelabuhan kapal tanker (minyak) dan pelabuhan penumpang yang menghubungkan Lombok dan Bali dengan kapal laut. Saat ini, yang tersisa hanyalah sebuah kapal bermuatan minyak, yang dapat dilihat tidak jauh dari pantai.

Keberadaan Lokasi Pantai Ampenan yang berada di Pusat Kota Tua Ampenan merupakan satu potensi yang dapat memperkuat citra kawasan. Jumlah kunjungan wisatawan setiap hari berkisar 150 sampai 500 orang. Khususnya sejak sore sampai malam hari.

Jaringan jalan di Kawasan Eks Pelabuhan Ampenan merupakan jalan arteri primer yang menghubungkan kawasan pantai (jalan Pabean) dengan simpang lima Jalan Raya Saleh Sungkar - Jalan Yos Sudarso - Jalan Ragi Genap dan Jalan Koperasi. Jalan di kawasan Pantai Ampenan ini mempunyai lebar lebih kurang 8 m. Pola pergerakan asal - tujuan pada wilayah perencanaan dapat diuraikan sebagai berikut : Untuk pergerakan internal, terdapat pergerakan antara Kota Tua Ampenan dan daerah sekitarnya. Untuk pergerakan ekternal, perjalanan umumnya menuju Luar Kecamatan Ampenan dan wilayah di sekitarnya.

Moda Transportasi mulai dari yang paling sederhana yaitu berjalan kaki, sepeda, sepeda motor, mobil 
pribadi, pickup atau kendaraan wisata. Sedangkan angkutan umum yang melintasi kawasan adalah cidomo, gocar atau gojek.

Dengan demikian, tingkat aksesibilitas kawasan Pantai Ampenan sangat tinggi. Selain karena Pantai Ampenan ini berlokasi di Kota Mataram bagian Barat dengan jarak tempuh dari pusat kota kurang lebih 15 menit. Lokasinya juga dapat dicapai dengan beragam moda transportasi.

\section{Analisa Sosial Budaya}

Penduduk di Kawasan Kota Tua Ampenan terdiri dari beragam suku. Hal ini terwujud dari banyaknya perkampungan sekitar yang menggunakan nama tempat asal mereka. Ada Kampung Tionghoa, Kampung Arab, Kampung Bugis, Kampung Melayu, Kampung Jawa, Kampung Bali, dan Kampung Banjar. Kehidupan multi etnik menjadi ciri khas Kota Tua Ampenan.

Ampenan merupakan sebuah kota utama atau kota tertua di Lombok sehingga di sepanjang perjalanan menuju pantai akan terlihat beberapa bangunan masih merupakan bangunan dengan gaya kolonial. Ampenan pernah menjadi pelabuhan penyeberangan utama yang menghubungkan Pulau Lombok dengan Pulau Bali. Namun, sejak tahun 1973 pelabuhan penyeberangan dipindahkan ke Lembar. Gelombang laut yang terlalu besar menjadi salah satu pertimbangan pemindahan. Sejak pemindahan pelabuhan penyeberangan ke Pelabuhan Lembar, kegiatan ekonomi masyarakat mengalami perubahan. Masyarakat suku Bugis paling banyak berprofesi sebagai nelayan. Warga Tionghoa dan Arab kebanyakan berdagang. Sedangkan suku lain beragam profesi. Masyarakat suku Sasak sendiri lebih banyak membuka warung makanan di bekas pelabuhan Ampenan. Sementara di dibagian Selatan terdapat kawasan perkampungan nelayan, yang sebagian besar penduduknya bermatapencaharian sebagai nelayan.

\section{Analisa SWOT}

Analisis kekuatan (strengths), kelemahan (weaknesses), peluang (opportunities), dan ancaman (threats) ini didasarkan pada pemikiran bahwa Pemerintah Kota Mataram nantinya harus memaksimalkan kekuatan dan peluang, serta meminimalkan kekurangan dan ancaman yang dimiliki oleh lokasi dan obyek penataan (wisata kuliner) yang direncanakan.

Tujuan dari analisis SWOT ini dapat digunakan untuk mengetahui keunggulan bersaing yang dimiliki oleh satu lokasi serta produk wisata yang direncanakan agar sesuai dengan keinginan konsumen dan mengoptimalkan peluang yang dimiliki oleh produk wisata tersebut.
Parameter yang akan digunakan dalam analisa SWOT, adalah:

- Jarak dan waktu tempuh dari pusat Kota Mataram

- Kemudahan pencapaian terkait kualitas sarana dan prasarana

- Luas lahan

- Kesesuaian dengan aturan Rencana Tata Ruang

- Ketersediaan fasilitas umum di masingmasing lokasi

- Kenyamanan, keamanan

- Aspek sosial dan budaya

- Kebersihan kawasan

\section{Analisa Faktor Internal}

a. Kekuatan (Strength)

1. Posisi lokasi dekat dari pusat Kota Mataram $\pm 5-6 \mathrm{~km}$. Waktu tempuh dari pusat kota ke Pantai Ampenan lebih lama 3 - 5 menit pada jam-jam sibuk karena harus melintasi jalur padat di Kota Tua Ampenan.

2. Kemudahan pencapaian (aksesibilitas) lokasi yang baik. Dapat langsung diakses dari jalan arteri yang mempunyai kualitas permukaan jalan hotmix yang bagus

3. Ketersediaan fasilitas umum seperti mushola, toilet, dan lain-lain sudah memadai.

4. Tersedianya sarana dan prasarana rekreasi anak (ayunan, seluncuran, papan jungkit, dll), dan juga tempat untuk swafoto.

5. Suasana di Pantai Ampenan cukup nyaman dan aman.

b. Kelemahan (Weaknesses)

1. Aspek kebersihan masih belum diperhatikan di ketiga lokasi. Sampah masih terlihat berserakan

2. Kondisi tata letak lapak pedagang di Pantai Ampenan belum menampakkan keteraturan. Masih banyak pedagang yang berjualan di luar zona. Hal ini mungkin disebabkan jumlah kunjungan wisatawan ke Pantai Ampenan cukup tinggi sementara kondisi pedagang cukup padat sehingga meja dan kursi tempat wisatawan makan dan minum tampak bertebaran tidak teratur dan membangkitkan kesan kumuh.

\section{Analisa Faktor Eksternal}

a. Peluang (Opportunities)

1. Pantai Ampenan secara aturan tata ruang layak dijadikan lokasi untuk wisata kuliner dengan tanpa melanggar pola pemanfaatan ruang Kota Mataram sesuai dengan RTRW Kota Mataram 2011-2031 dan Perda Kota Mataram No. 5 tahun 2019 tentang Perubahan Atas Peraturan Daerah RTRW Kota Mataram tahun 2011-2031. 
2. Tingginya minat wisatawan terhadap kuliner. Menu masakan berbahan baku ikan sangat diminati oleh wisatawan yang berkunjung ke Pulau Lombok. Selain itu, juga menu khas Nusa Tenggara Barat seperti plecing kangkung, ayam taliwang, sepat, bebalung juga disukai oleh wisatawan. Ini menjadi peluang yang sangat besar bagi masyarakat/penduduk setempat.

b. Ancaman (Threats)

1. Belum banyak tersedia transportasi umum. Meskipun lokasi berada dekat pusat kota, tetapi bila tidak tersedia atau jarang ada transportasi umum yang menuju lokasi akan menjadi satu ancaman hilangnya minat pengunjung untuk datang ke lokasi. Karena bagi para pengunjung yang tidak menggunakan kendaraan pribadi akan mengalami kesulitan untuk mengunjungi lokasi.

2. Masih kurangnya dukungan obyek wisata lain. Adanya obyek wisata lain di lokasi akan menarik minat para pengunjung untuk datang. Tidak hanya itu, pengunjung juga dapat memperpanjang waktu kunjungan. Tapi jika di lokasi hanya mengandalkan wisata kuliner sebagai destinasi wisata, ini dapat menjadi ancaman untuk membuat tempat wisata kuliner sustainable.

\section{Kesimpulan}

Berdasarkan hasil analisa kesesuaian lahan, lingkungan, sosial budaya, dan juga SWOT yang dimiliki, maka dapat ditarik satu kesimpulan bahwa Pantai Ampenan layak dan sangat berpotensi untuk dijadikan lokasi Tempat Wisata Kuliner Kawasan Pantai di Kota Mataram, karena:

1. Posisi lokasi yang dekat dari pusat Kota Mataram

2. Posisi lokasi terhadap Kota Tua Ampenan yang akan saling bersinergi untuk memperkuat citra kawasan, dan sekaligus mendukung revitalisasi kawasan Kota Tua Ampenan.

3. Kemudahan pencapaian (aksesibilitas) lokasi

4. Luas lahan yang mencukupi untuk dilakukan penataan dan pengembangan

5. Ketersediaan fasilitas umum

6. Ketersediaan sarana dan prasarana

7. Kenyamanan dan keamanan

8. Kesesuaian dengan Rencana Pola Pemanfaatan Ruang Wilayah

9. Tingginya minat wisatawan terhadap kuliner berbahan baku ikan dan kuliner khas Nusa Tenggara Barat.

Selain potensi, kekuatan dan peluang yang ada, rencana penataan tempat wisata kuliner di Kawasan Pantai Ampenan ini perlu mempersiapkan strategi menghadapi beberapa permasalahan yang akan muncul, yaitu:

1. Masalah kebersihan lokasi penataan perlu mendapat perhatian Pemerintah Kota Mataram. Selain penyediaan tempat sampah yang harus diangkut secara rutin, Pemerintah Kota Mataram juga sebaiknya melakukan pemantauan secara berkala untuk melihat kondisi lokasi. Harus ada sanksi untuk lapak pedagang yang kumuh atau yang membiarkan sampahnya berserakan. Bentuk sanksi dapat berupa denda atau skors ijin berjualan selama beberapa hari.

2. Untuk meningkatkan keamanan lingkungan kawasan dan menambah kenyamanan wisatawan, terutama di malam hari. Maka perlu ada penambahan penerangan.

3. Pemerintah Kota Mataram dan pengelola kawasan perlu menyusun strategi operasional dalam penataan objek wisata kuliner di Pantai Ampenan ini agar tetap menonjolkan unsur pendidikan-etika-moral dan budaya.

\section{Daftar Pustaka}

Besra, Eri. (2012). Potensi Wisata Kuliner Dalam Mendukung Pariwisata di Kota Padang. Jurnal Riset Akuntansi dan Bisnis, 12(1), 74-101.

Boyne, S., Williams, F., \& Hall, D. (2002). The Isle of Arran taste trail. In A. M. Hjalager \& G. Richards (Eds.), Tourism and gastronomy (pp. 91-114). London, England: Routledge.

Juliana. (2019). Analisis Potensi Kawasan Wisata Kuliner Dalam Mendukung Pariwisata di Kota Tegal, Jawa Tengah. Jurnal Khasanah Ilmu, 10(2), 99-105.

Kivela, J., Crotts, J.C. (2005). Gastronomy Tourism. Journal of Culinary Science \& Tourism, 4(2-3), 3955.

Mitchell, R., \& Hall, M. C. (2003). Consuming tourist: Food tourism consumer behaviour. In M. C. Hall, L. Sharples, R. Mitchell, N. Cambourne, \& N. Macionis (Eds.), Food tourism around the world: Development, Management and Markets (pp. 60-80). Oxford: Butterworth-Heinemann.

Pepela, A., \& O'Halloran, R. M. (2014). Targeting Kenya's coastal gastronomic market: An assessment of tourists' demographics (in review).

Pemerintah Kota Mataram. (2019). Peraturan Daerah Kota Mataram No. 5 Tahun 2019 Tentang Perubahan Atas Peraturan Daerah Rencana Tata Ruang Wilayah Kota Mataram tahun 2011-2031.

Suteja, I Wayan., \& Wahyuningsih, Sri. (2019). Strategi Pengembangan Potensi Kuliner Lokal dalam Menunjang Kegiatan Pariwisata di Kawasan Ekonomi Khusus Mandalika, Kabupaten Lombok Tengah. E-Jurnal Binawakya, 14(2), 2035-2042.

Wijayanti, Ani. (2020). Wisata Kuliner Sebagai Strategi Penguatan Pariwisata di Kota Yogyakarta, Indonesia. 
Khasanah Ilmu: Jurnal Pariwisata dan Budaya, 11(1), 74-82.

Wulandari, E., Utami, A.R., \& Purwanti, Titik. (2019).

Daya Tarik Wisata Kuliner di Kota Bandung (Studi Kasus Pada Wisata Kuliner Dago). Jurnal Education and Economics, 02(03), 389-394. 